\title{
Growth and reproduction of an estuarine population of the colonial hydroid Cordylophora caspia (Pallas) in the northern Baltic Sea
}

\author{
V. Jormalainen, T. Honkanen, T. Vuorisalo \& P. Laihonen \\ Department of Biology, Laboratory of Ecology and Animal Systematics, \\ University of Turku; FIN-20500 Turku, Finland
}

\begin{abstract}
Growth and reproduction of the colonial hydroid Cordylophora caspia were monitored during the breeding season in natural conditions. In 1987, a life history study was carried out on the upright stems of the main stolon. Mean size of uprights varied cyclically. The first peak coincided with the peak number of sexual hydranths, after which the mean upright length decreased, possibly indicating somatic costs of sexual reproduction. Extrinsic factors like flooding may also have contributed to cyclical changes in upright size. In 1988 and 1989, colonies were reared on experimental plates in the estuary. In 1988, colonies grew until mid July, after which they regressed to a dormant condition and then started growing again in mid August. Predation and space competition are discussed as possible causes for this dormancy in the middle of the growing season. In 1989 , colonies grew continually, with the exception of a decline in colony biomass and number of feeding hydranths at the end of July, just following the peak of sexual reproduction. Sexual reproduction started in the early stages of colonial development for all years. During early summer, C. caspia allocated resources simultaneously in colonial growth and sexual reproduction. However, sexual reproduction had a clear peak in mid summer, and thereafter sexual reproduction ceased while colonial growth continued.
\end{abstract}

\section{INTRODUCTION}

Life-history characteristics of modular and unitary animals differ considerably. At the genet level, they probably do not have senescence; thus, the clones may be functionally immortal on ecological time scales (Palumbi \& Jackson, 1983). In colonial hydroids, the absence of senescence may be possible also for single colonies or structural individuals (sensu Vuorisalo \& Tuomi, 1986) by means of continual cellular regeneration (Tardent, 1963). As a consequence, the lifetime reproductive output of the colonies approaches infinity (Jackson \& Coates, 1986), and because of partial mortality, fragmentation, and fusion, colony size correlates poorly with age (Hughes, 1984; Jackson \& Hughes, 1985). For genetic or structural units, modular animals go far beyond the concepts of classical life-history theory (Sackville Hamilton et al., 1987), which complicates the study of their population dynamics. The definition of the relevant unit of the study may be especially difficult (Harper, 1981).

Modular organisms consist of repetitive, partially self-maintaining, multicellular structures (Vuorisalo \& Tuomi, 1986), or simply repeated units of multicellular structure (Harper, 1981). The partial functional autonomy of modules makes it possible to study the life-history of modules; modules have a definite lifespan and usually are the structures 
carrying reproductive organs. In the field, it is also often easier to count modules than genets or structural individuals (Harper, 1981).

Growth and physiology of colonial hydroids have been studied in the laboratory (e.g. Kinne, 1956; Crowell, 1957; Fulton, 1962, 1963; Braverman, 1963); but there are few population studies which include observations about life histories in natural conditions (Boero, 1984; see also Pyefinch \& Downing, 1949; Kinne, 1956; Roos, 1979; Hughes, 1977. 1986). Generally, competition (e.g. Rinkevich \& Loya, 1985; Buss, 1990) and predation (e.g. Colgan, 1987) are suggested to be important factors affecting growth, reproductive output and mortality of clonal invertebrates. The intensity of competition and predation also may be connected to initiation of sexual reproduction in some colonial invertebrates (Harvell \& Grosberg, 1988).

Cordylophora caspia colonies in the northern Baltic are perennial, with a seasonal regression-regeneration cycle. During the winter, colonies regress into dormant stolons. The colony grows by iterating modular units, namely polyps or hydranths. The main stolon is attached to the substratum, and hydranths form upward structures called hydrocauli (Fulton, 1962) or uprights (Crowell, 1957) by growing in length and forming branches. Reproductive structures, called gonophores, branch from stems of hydranths, and there is no medusa stage. Thus, the structure of $C$. caspia is modular at two hierarchical levels. At least, either a hydranth or an upright, as in the present study, can be considered as a module.

This study describes the life history of a natural population of the colonial hydroid $C$. caspia (Pallas) at both modular and colonial levels. Samples of uprights were taken from natural settlement sites, and the growth and reproductive state were analysed. The growth of colonies that were attached to experimental plates was monitored during the growing season.

\section{MATERIAL AND METHODS}

\section{Sampling}

Samples of Cordylophora caspia were taken weekly (19th June-18th August) in 1987 from the river Aurajoki in Turku, Finland. The river Aurajoki empties into the Baltic Sea and forms an estuary about $4 \mathrm{~km}$ in length. Samples were taken from 7 to 10 different locations along the estuary. Salinity varies, being near brackish water during most of the growing season, and freshwater during high waterflow. The growing depth varied from 1 to $2 \mathrm{~m}$, and the usual substratum was a dock's wooden buttress. Samples were preserved in $70 \%$ alcohol for further analysis in the laboratory.

The upright samples were analysed. Ten uprights were randomly selected from each sample. An upward stem with two or more hydranths was considered as an upright, except that when the upright had remains of dead hydranths, it was counted as an upright, even with only one hydranth. Single hydranths growing from the old stolon were not counted. The length (mm), number of hydranths, number of gonophores and developmental stage were measured from the uprights and, when possible, the sex was determined. The developmental stages of gonophores were divided into three classes: class 1 was recently budded, small, and had no visible internal structure; class 2 was intermediate in size and had some visible internal structure; class 3 was a mature gonophore in which sex determination was possible (Schulze, 1871). 


\section{Monitoring the colony growth}

Growth dynamics of $C$. caspia at the colonial level were studied during the summers of 1988 and 1989. As the distinction of separate structural individuals from the natural samples was practically impossible, plates were placed with artificially attached colonies in natural growing sites and growth was monitored. For this purpose, parts of dormant colonies were sampled from several places along the river Aurajoki at the beginning of June 1988 and May 1989. The pieces of stolons sampled from different sites were used to start separate experimental clones. As soon as a few hydranths emerged from these stolons in the laboratory, the hydranths were cut, removed, set on 9 - by $18-\mathrm{cm}$ plastic plates, and allowed to grow. Each hydranth started a colony. Colonies originating from the same part of a stolon formed an experimental clone.

Ten plates, all representing different clones, were tied into each of several plastic shopping baskets. The colonies were transferred to the field site and placed at a depth of 1-2 m on 21st June 1988 and on 31st May 1989. In 1988, all of the baskets were kept within the same area, and the maximum distance between the baskets was about $100 \mathrm{~m}$. In 1989, we had baskets with the same clones in two different locations along the river, but since there were no growth differences between the locations, the results were combined.

The growth and the reproductive status of the clones were recorded by analysing one randomly selected basket of the colonies weekly in the laboratory. The size of a colony was measured either as the number of hydranths or as dry weight $\left(24 \mathrm{~h}\right.$ at $\left.70^{\circ} \mathrm{C}\right)$ of the colony. Length and the number of hydranths and gonophores were measured from 15 (1988) or 20 (1989) randomly selected uprights from each colony. At this time, single hydranths emerging from the stolons were also counted as uprights.

We also studied the timing of reproduction and the recruitment in 1988 by placing empty $9 \times 18 \mathrm{~cm}$ plates near the experimental colonies and counting the newly settled $C$. caspia larvae. The plates were tied into two different baskets, 5 to 7 plates in each, and the larvae that settled were counted weekly, and the old plates were replaced by new ones. Larvae are ready to attach to the substratum immediately after release from the gonophore; thus, there was practically no time lag between recruitment and attachment.

\section{RESULTS}

\section{Growth and reproduction of uprights}

In the first sample, 19th June 1987, a few hydranths had just budded from the stolon stems after winter dormancy and the uprights consisted of 3 to 4 hydranths on average. After that, uprights grew rapidly in length, reaching the first maximum on 15th July (Figs $1,2)$. However, by the next sample, on 22 nd July, the average length of uprights had decreased significantly (Table 1). In the sample on 30th July, the upright length had returned to the level of mid-July, and similar cyclic changes in upright length also occurred later in the season (Fig. 1, Table 1).

The decrease in the average length on both 22nd July and 11th August resulted from the mortality of the longest (over $25 \mathrm{~mm}$ ) uprights and possibly also from the incapacity of the smaller ones to reach greater sizes (Fig. 2). In August, there was great variability in 


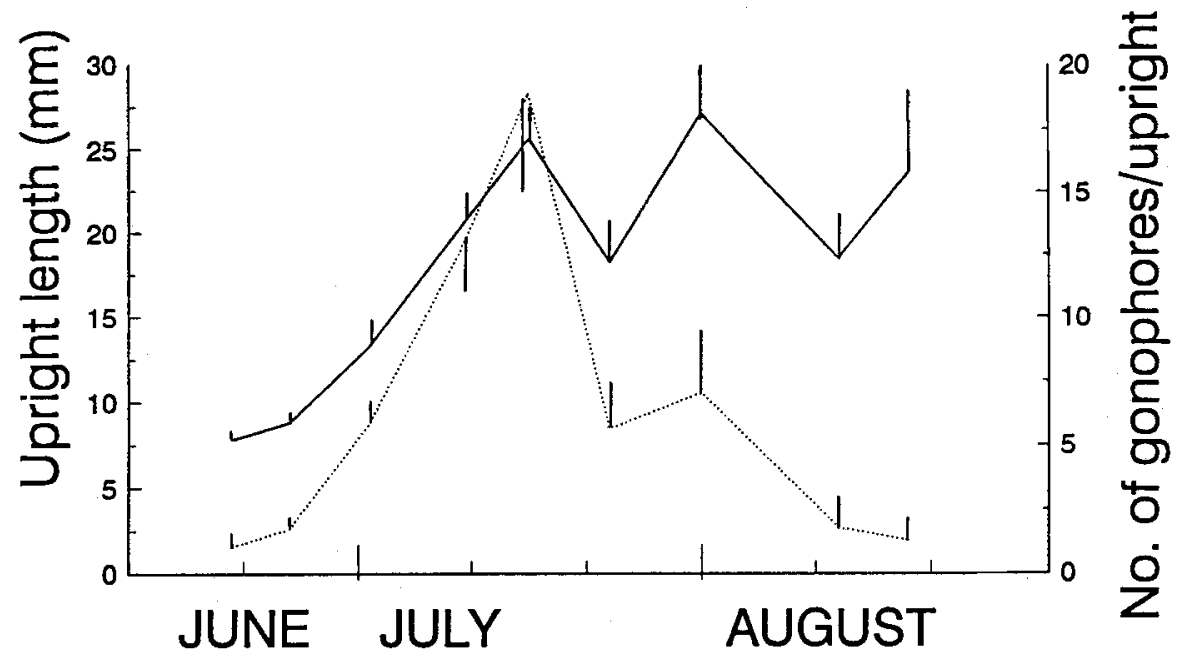

Fig. 1. Mean length of uprights (solid line) and mean number of gonophores per upright (dotted line) with $99 \%$ confidence limits during Summer 1987 . For sample sizes, see Table 1

size, as the lengths ranged from less than 5 to over $50 \mathrm{~mm}$ (Fig. 2). The negligible amount of uprights under $5 \mathrm{~mm}$ in length is an artefact due to the definition of an upright as a complex of two or more hydranths.

Reproduction began early in June, and the reproductive peak coincided with the first peak in upright length on 15th July (Fig. 1). The number of gonophores declined quickly thereafter, with the exception of a minor increase on 30th July. In the first two samples, about one half of the uprights were reproductive, while in all samples from July, over $80 \%$ were carrying gonophores (Fig. 2). In the last two samples from August, only about $30 \%$ were reproducing (Fig. 2). During the reproductive peak (9th July-22nd July), the reproductive effort of uprights, calculated as the number of gonophores per number of total hydranths, correlated positively with the upright length $(\mathrm{r}=0.368, \mathrm{p}<0.001 ; \mathrm{r}=$ $0.234, \mathrm{p}<0.05 ; \mathrm{r}=0.518, \mathrm{p}<0.001$, for 9 th, 15th and 22nd July respectively). The sex ratio was strongly biassed towards the females in all samples (males/females in pooled material $=0.28$ ).

The first gonophores appeared in proximal feeding hydranths of an upright, and the budding continued towards the terminal hydranths. In the first sample on 19th June, only

Table 1. Student-Newman-Keuls test statistics of the differences in upright length during Summer 1987. The dates with different letters differ significantly at the level of $5 \%$ ( $d f=767$ ). Data from Figure 1

\begin{tabular}{|cccccccccc|}
\hline \multicolumn{3}{|c}{ June } & \multicolumn{4}{c}{ July } & \multicolumn{3}{c}{ August } \\
& 19 th & 24 th & 1st & 9 th & 15th & 22 nd & 30th & 11th & 18th \\
\hline n & 90 & 103 & 100 & 89 & 95 & 70 & 84 & 101 & 44 \\
& A & A & B & C & E & C & E & C & D \\
& & & & D & & & & \\
\hline
\end{tabular}




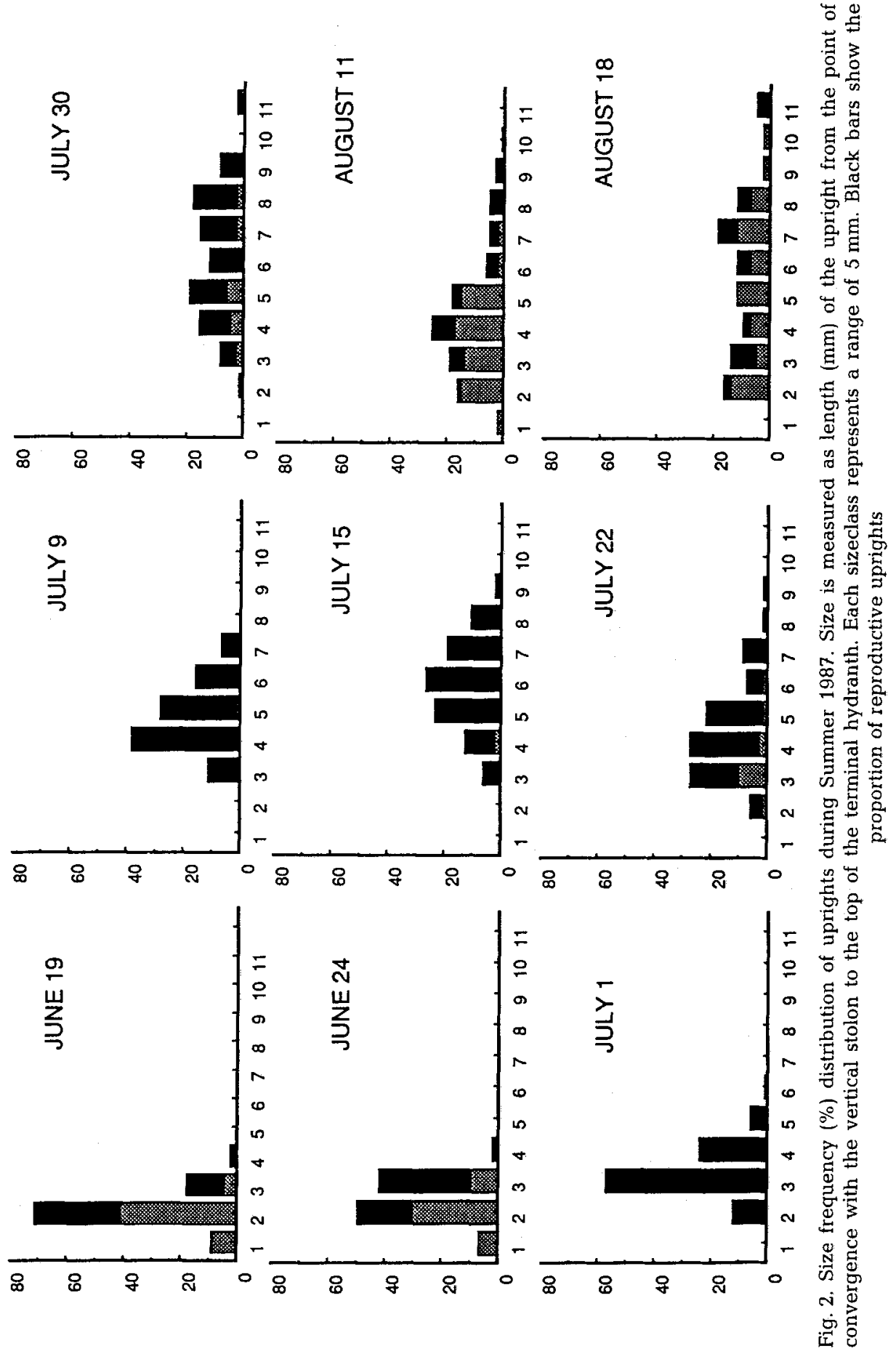


gonophores at developmental stages 1 and 2 were present, indicating that the reproductive period commenced in mid June. Later, all developmental stages were found, and $90 \%$ of the uprights simultaneously carried gonophores at different stages. The peak frequency of mature gonophores coincided with the time of maximum number of gonophores, and mature gonophores were most abundant when the uprights were at the longest length (15th and 30th July, 18th August). Interestingly, in the last sample on 18th August, the frequency of gonophores at the first developmental stage was higher than in the two previous samples, possibly indicating reinitiation of gonophore production.

The number of eggs per gonophore declined slightly from July to August (Table 2). The regression coefficient between sampling time and mean egg-number/gonophore/ upright was negative ( $\mathrm{df}=103, \mathrm{~b}=-0.082, \mathrm{a}=12.8, \mathrm{P}<0.001$ ).

Table 2. Mean number of feeding hydranths per upright, reproductive effort of uprights, and number of eggs in a mature female gonophore in successive samples during Summer 1987. Means with different letters differ significantly at the level of $5 \%$ (Student-Newman-Keuls test)

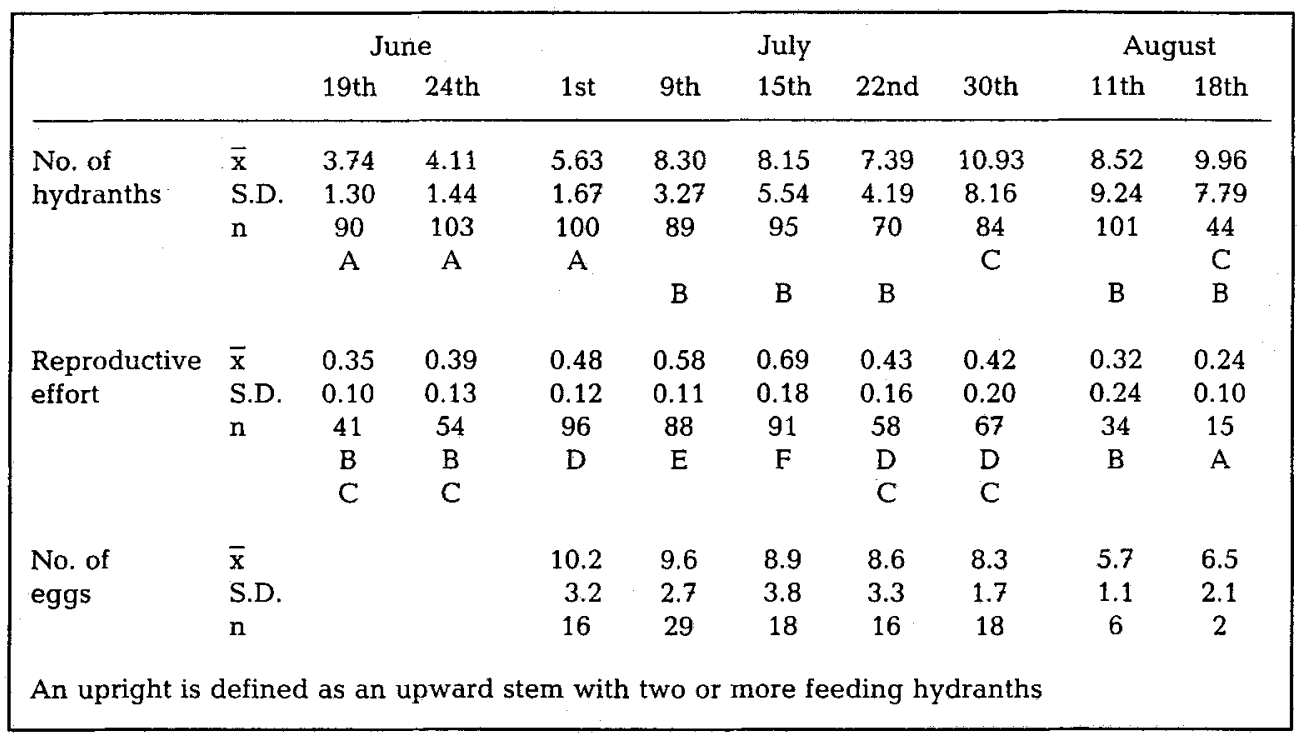

The number of feeding hydranths per upright increased smoothly during the growing season (Table 2). The maximum number of hydranths was found on 30 th July, at the time of the second peak in length, but well after the reproductive peak. The uprights thus appeared to shift their allocation of resources from the early season growth to sexual reproduction during mid-summer, and back to growth (asexual reproduction) in late summer, which is also indicated by the reproductive effort in successive samples (Table 2).

\section{Growth of colonies}

On 21st June 1988, colonies with an average size of 7.1 hydranths per colony ( $S D=$ $3.8, \mathrm{n}=90$ ) were placed into the estuary, and thereafter grew rapidly, producing gonophores until 19th July (Fig. 3a, Table 3). Although the total size of colonies 

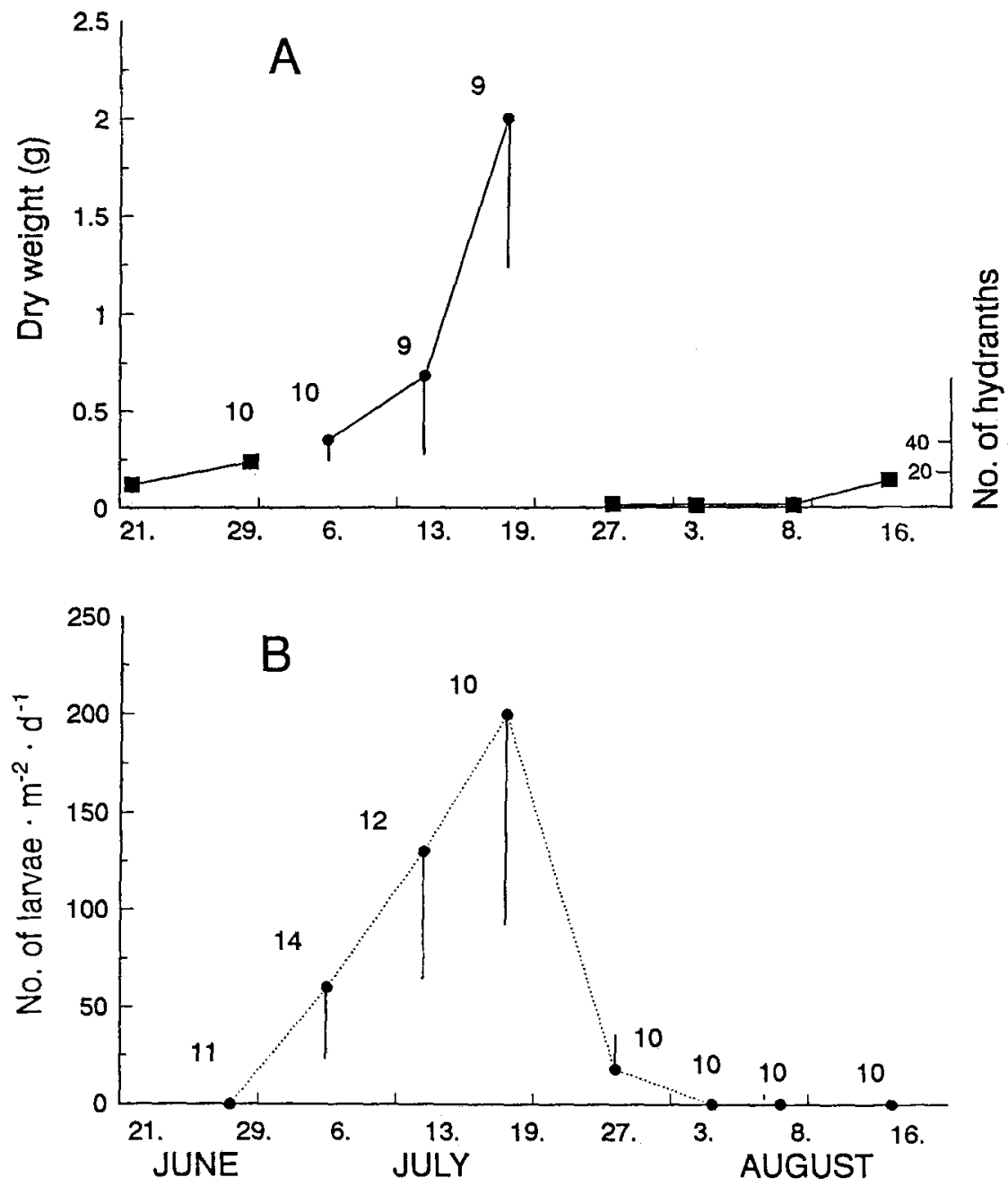

Fig. 3. A: Growth of colonies on experimental plates during Summer 1988. Size was measured either as a number of individual hydranths (squares) or as dry weight of the colony (circles). 99\% confidence limits as well as sample sizes are shown. B: The settlement rate (mean, $99 \%$ confidence limit) of C. caspia larvae during Summer 1988

increased, the average number of hydranths (ANOVA: $d f=2,26, F=1.3$ ) or gonophores (ANOVA: $\mathrm{df}=2,27, \mathrm{~F}=0.5$ ) per upright did not differ significantly between the three successive samples (Table 3 ).

During the next week (19th-27th July), colonies lost all living hydranths and appeared dead until 16th August, when they recommenced the production of feeding hydranths. One colony also began to reproduce.

The data from the larval settlement rates in the same area (Fig. 3b) are consistent with the life-history events of the colonies. Both the reproductive peak on 19th July and the quick cessation of reproduction after that coincided with changes in larval settlement. 
Table 3. Mean number of hydranths and gonophores per upright in a colony for three successive samples during Summer 1988

\begin{tabular}{|c|c|c|c|c|c|}
\hline & \multicolumn{2}{|c|}{ No. of hydranths } & \multicolumn{2}{|c|}{ No. of gonophores } & \multirow[b]{2}{*}{$\mathrm{n}$} \\
\hline & $\overline{\mathbf{x}}$ & S.D. & $\overline{\mathrm{x}}$ & S.D. & \\
\hline 6th July & 3.29 & 1.20 & 2.14 & 1.60 & 10 \\
\hline 13th July & 4.10 & 1.41 & 3.11 & 2.52 & 10 \\
\hline 19th July & 2.82 & 2.37 & 2.50 & 2.36 & 10 \\
\hline
\end{tabular}

Table 4. Frequencies of the colonies containing different amounts of egg-pouches of Embletonia pallida in June and July 1988. Egg-pouches were not found in other samples

\begin{tabular}{|lccr|}
\hline $\begin{array}{l}\text { Frequency } \\
\text { class }\end{array}$ & $\begin{array}{c}\text { June } \\
19 \text { th }\end{array}$ & 27 th & July \\
\hline None & 7 & 0 & 3rd \\
Some pouches & 1 & 3 & 5 \\
Many & 1 & 6 & 3 \\
Very many & 1 & 1 & 0 \\
No. of colonies observed & 10 & 10 & 20 \\
\hline
\end{tabular}

In this respect, the behaviour of the natural colonies was similar to that of our experimental colonies.

When the colonies were at their largest (19th July), and for two weeks thereafter, egg-pouches of an opisthobranchian slug Embletonia pallida were found attached to the colonies (Table 4). The large number of egg-pouches on colonies presumably indicates greatly increased grazing pressure at the time.

In 1989, living hydranths were found in the experimental colonies throughout the whole monitoring period. The colonies gained weight from 15 th June to 12th July, after which they at first slightly lost weight, then again regained weight (Fig. 4). Colonies started to reproduce soon after they were transferred into the river, and the peak numbers of feeding hydranths and gonophores coincided (Fig.5). After that, sexual reproduction ceased almost completely (Fig. 5).

\section{DISCUSSION}

\section{Upright dynamics}

The growth of Cordylophora caspia showed a cyclical pattern at the level of uprights. These cyclical changes in the mean upright length may result either from (1) phenomena at the colonial level, such as recruitment of new colony generations, or the regressionreplacement cycle of the existing colonies, or (2) module population dynamics (Harper, 1981) as a consequence of the module life-histories and mortality factors operating within 


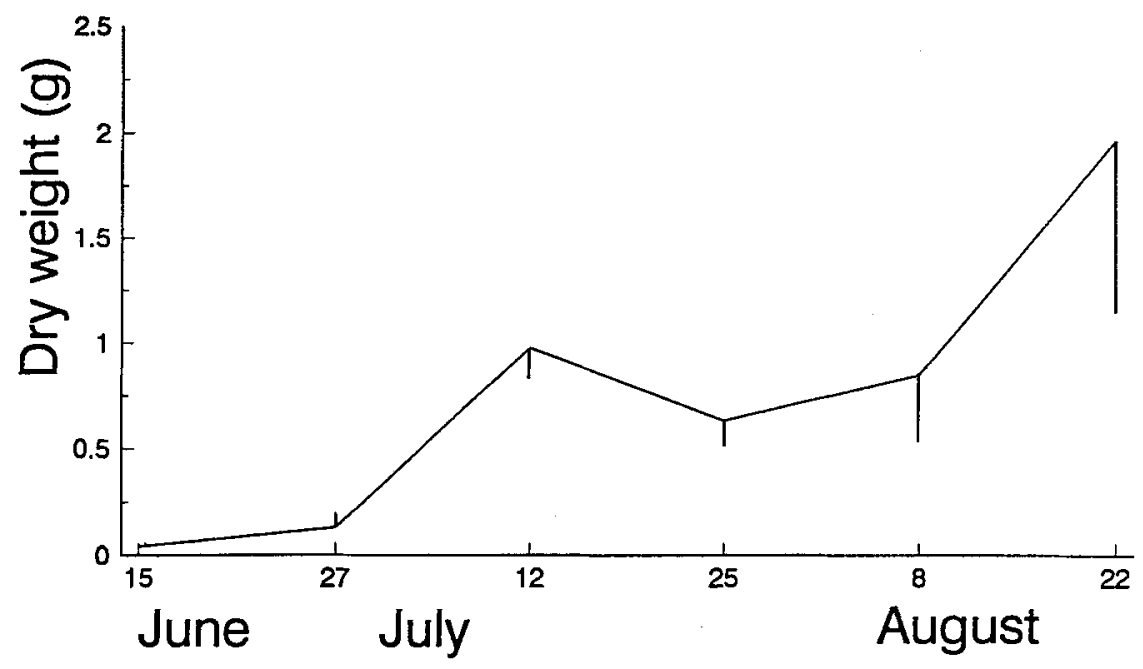

Fig. 4. Growth of colonies (mean, SE) on experimental plates during Summer 1989, measured as dry weight $(g)$ of a colony

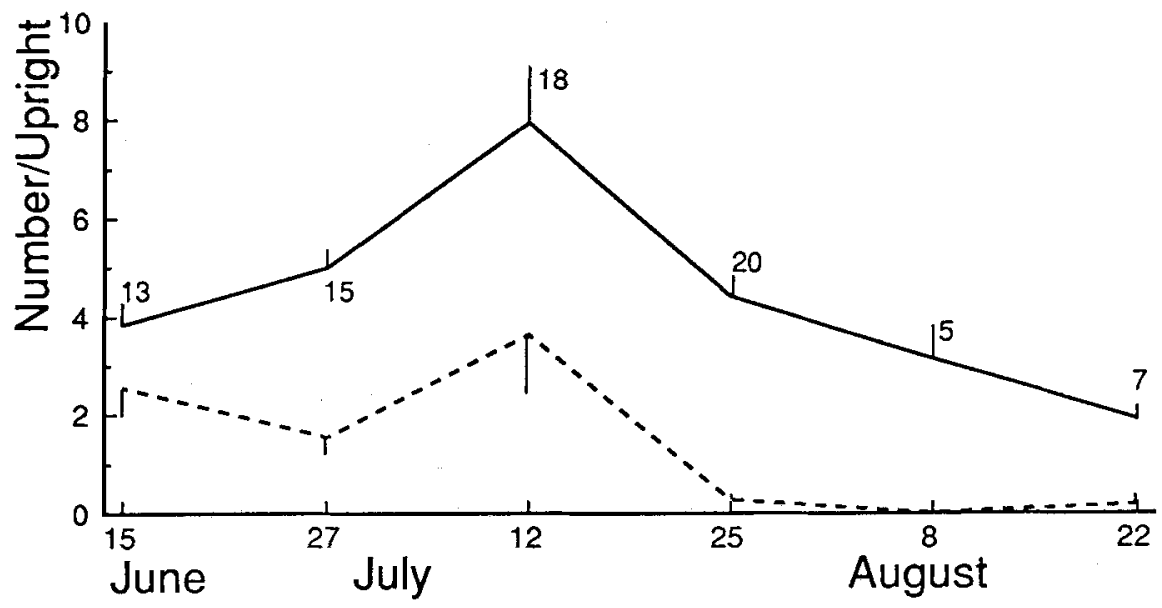

Fig. 5. Number of feeding hydranths (solid line) and gonophores (dotted line) per upright (mean, SE) in colonies during Summer 1989. Each measurement within a colony is based on a random sample of 20 uprights

colonies. Our observations suggest the latter alternative; we have no evidence of the degeneration or senescence of whole colonies in 1987.

The successive cycles in upright length may have multiple causes. The first peak in upright length (15th July) coincided with the peaks in reproductive effort, the frequency of reproductive uprights and the number of mature gonophores. The subsequent decrease in mean upright length is probably due to senescence of older uprights. This hypothesis is supported by our observation that uprights carrying empty gonophores were definitely in poor condition. The poor growth performance of the smaller size 
classes at the same time may result from the allocation of resources into sexual reproduction instead of growth.

At the beginning of August 1987 ( 7 th-11th), the highest daily waterflow of the swollen river Aurajoki was over 200 times the mean daily flow in July. Just after the flood, the uprights were rare and seemingly in poor condition. Mortality engendered by the flood may have been size-selective against longer uprights and may be responsibe for the low mean length in the sample of 11 th August. The death of uprights after reproduction may also have contributed to the decline on 11 th August, before which there was also a minor peak in the frequency of mature gonophores.

\section{Dormancy during growing season?}

The dynamics of the colonies in the summers of 1988 and 1989 differed. In 1988 , colonies started to reproduce soon after being placed in natural conditions, growing in size until 19th July. However, all hydranths were subsequently lost and the colonies remained dormant until mid-August. Larval recruitment also stopped simultaneously, indicating that parallel events occurred in all nearby colonies.

Dormancy in colonial hydroids is commonly connected to changes in the environment (Tardent, 1963; Hughes, 1986), especially a decrease in water temperature; but also other stresses, like starvation or salinity changes, are suggested to induce dormancy (Tardent, 1963). Generally, dormancy is one way to reduce the body to a small and relatively invulnerable stolon that can survive in an otherwise lethal environment (Hughes, 1986). This behaviour can be performed by individual modules, whole colonies, or entire populations, according to the magnitude of the external pressure (Tardent, 1963). C. caspia colonies become dormant when the water temperature decreases to below $4{ }^{\circ} \mathrm{C}$ (Kinne, 1956), but dormancy during the growing season had not been reported previously. Summer dormancy occurs for some other hydroid species in warmer seas (Hughes, 1989).

The induction of dormancy in mid summer may be connected, for example, with increased space competition, predation pressure, starvation or a catastrophic event. The colonies on the experimental plates, as in nature, possibly competed for space with Balanus and Cordylophora larvae. Competition with Balanus especially may have become more severe during the growing season, as both Balanus and the colonies grew in size.

Predation by the opisthobranchian slug Embletonia pallida may have contributed to the induction of dormancy. This specialized predator of $C$. caspia (Todd, 1981) was abundant in the area from 19th June to 3rd July. Generally, predation-induced changes in morphology have been found in some colonial invertebrates (Harvell, 1984, 1991). There is also some evidence that nudibranch predation may induce changes in growth form in C. caspia (Gaulin et al., 1986). Such predator-induced dormancy could be an efficient way to escape local predation pressure.

\section{Timing of sexual reproduction}

Most modular animals reproduce sexually by zygotes and also asexually by iterated growth of modular units (zooids, polyps), followed often by fragmentation of colonies 
(Hughes, 1987, 1989). This has raised the question concerning what conditions affect the shift between different modes of reproduction. Harvell \& Grosberg (1988) studied experimentally the timing of sexual maturity in a bryozoan (Membranipora membranacea) and a colonial ascidian (Botryllus schlosseri) species and concluded that extrinsic factors like substratum limitation, crowding by conspecifics, and simulated grazing triggered the onset of sexual maturity. They also stressed that the timing of sexual maturity is often phenotypically plastic and may involve complex interactions between intrinsic and environmental factors. Sexual reproduction may also require a certain minimum colony size (Jackson \& Hughes, 1985).

Natural colonies of $C$. caspia began to reproduce sexually shortly after winter dormancy, while the experimental colonies started to produce gonophores shortly after being immersed in the estuary, well before space became limiting. Furthermore, the number of eggs in female gonophores was highest shortly after winter dormancy. Thus, the initiation of sexual reproduction in $C$. caspia does not seem to require extrinsic limitations of growth, and sexual and somatic allocation proceed simultaneously. However, the period of strong sexual reproduction was short compared to the length of the growing period.

Sexual reproduction seems to be costly for both uprights and whole colonies. In 1987, the uprights died after strong sexual reproduction. In 1989, immediately after peak gonophore production, colonies lost weight and the mean number of feeding hydranths per upright decreased, probably as a consequence of the death of old and large reproductive uprights. However, the uprights recommenced growth in length by the end of July.

C. caspia shifted resource allocation from an early season of strong sexual reproduction to production of feeding hydranths after mid summer. If the size of the colony is negatively correlated with mortality (see e.g. Hughes, 1984; Hughes \& Jackson, 1985; Karlson, 1986) during winter dormancy, it would be a reasonable tactic to increase the biomass during late summer and adjust larval reproduction to early season.

Acknowledgements. We thank E. Haukioja for comments on an earlier version of this manuscript, and J. Vranjic for checking the language. A part of the work was financially supported by the Turku University Foundation, and V. J. enjoyed a grant from the KONE foundation during the preparation of the manuscript. The Archipelago Research Institute of the University of Turku kindly offered us a boat and research facilities.

\section{LITERATURE CITED}

Boero, F., 1984. The ecology of marine hydroids and effects of environmental factors: A review. Mar. Ecol. 5, 93-118.

Braverman, M. H., 1963. Studies on hydroid differentiation; II. Colony growth and the initiation of sexuality. - J. Embryol. exp. Morph. 11, 239-253.

Buss, L. W., 1990. Competition within and between encrusting clonal invertebrates. - Trends Ecol. Evolut. 5, 352-356.

Colgan, M. W., 1987. Coral reef recovery on Guam (Micronesia) after catastrophic predation by Acanthaster planci. - Ecology 68, 1592-1605.

Crowell, S., 1957. Differential responses of growth zones to nutritive level, age, and temperature in the colonial hydroid Campanularia. - J. exp. Zool. 134, 63-90.

Fulton, C., 1962. Environmental factors influencing the growth of Cordylophora. - J. exp. Zool. 151, 61-78. 
Fulton, C., 1963. The development of a hydroid colony. - Devl Biol. 6, 333-369.

Gaulin, G., Lauren, D., Beaulieu, J. \& Harris, L. G., 1986. Predation-induced changes in growth form in a nudibranch-hydroid association. - Veliger 28, 389-393.

Harper, J. L., 1981. The concept of population in modular organisms. In: Theoretical ecology: principles and applications. Ed. by R. M. May. Blackwell, Oxford, 53-77.

Harvell, C. D., 1984. Predator-induced defenses in a marine bryozoan. - Science, N.Y. 224, $1357-1359$.

Harvell, C. D., 1991. Coloniality and inducible polymorphism. - Am. Nat. 138, 1-14.

Harvell, C. D. \& Grosberg, R. K., 1988. The timing of sexual maturity in clonal animals. - Ecology 69, 1855-1864.

Hughes, R. G., 1977. Aspects of the biology and life-history of Nemertesia antennina (L.) (Hydrozoa: Plumulariidae). - J. mar. biol. Ass. U.K. 57, 641-657.

Hughes, R. G., 1986. Differences in the growth, form and life history of Plumularia setaceae (Ellis \& Solander) (Hydrozoa: Plumulariidae) in two contrasting habitats. - Proc. R. Soc. Lond. (B) 288, 113-125.

Hughes, R. N., 1987. The functional ecology of clonal animals. - Func. Ecol. 1, 63-69.

Hughes, R. N., 1989. A functional biology of clonal animals. Chapman \& Hall, London, $331 \mathrm{pp}$.

Hughes, T. P., 1984. Population dynamics based on individual size rather than age: a general model with a reef coral example, - Am. Nat. 123, 778-795.

Hughes, T. P. \& Jackson, J. B. C., 1985. Population dynamics and life histories of foliaceous corals. Ecol. Monogr. 55, 141-166.

Jackson, J. B. C. \& Coates, A. G., 1986. Life cycles and evolution of clonal (modular) animals. - Phil. Trans. R. Soc. Lond. (B) 313, 7-22.

Jackson, J. B. C. \& Hughes, T. P., 1985. Adaptive strategies of coral-reef invertebrates. - Am. Scient. 73, 265-274.

Karlson, R. H., 1986. Disturbance, colonial fragmentation, and size-dependent life history variation in two coral reef cnidarians. - Mar. Ecol. Prog. Ser. 28, 245-249.

Kinne, O., 1956. Über den Einfluß des Salzgehaltes und der Temperatur auf Wachstum, Form und Vermehrung bei dem Hydroidpolypen Cordylophora caspia (Pallas), Thecata, Clavidae. - Zool. Jb. (Abt. allg. Zool. Physiol. Tiere), 66, 565-638.

Palumbi, S. R. \& Jackson, J. B. C., 1983. Aging in modular organisms: ecology of zooid senescence in Steginoporella sp. (Bryozoa; Cheilostomata). - Biol. Bull. mar. biol. Lab., Woods Hole 164, $267-278$.

Pyefinch, K. A. \& Downing, F. S., 1949. Notes on the general biology of Tubularia larynx Ellis \& Solander. - J. mar. biol. Ass. U. K. 28, 21-43.

Rinkevich, B. B. \& Loya, Y., 1985. Intraspecific competition in a reef coral: effects on growth and reproduction. - Oecologia $66,100-105$.

Roos, P. J., 1979. Two-stage life cycle of a Cordylophora population in the Netherlands. - Hydrobiologia $62,231-239$.

Sackville Hamilton, N. R., Schmid, B. \& Harper, J. L., 1987. Life-history concepts and the population biology of clonal organisms. - Proc. R. Soc. Lond. (B) 232, 35-57.

Schulze, F. E., 1871. Über den Bau und die Entwicklung von Cordylophora lacustris (Allman). Engelman, Leipzig, $52 \mathrm{pp}$.

Tardent, P., 1963. Regeneration in the Hydrozoa. - Biol. Rev. 38, 293-333.

Todd, C. D., 1981. The ecology of nudibranch molluscs. - Oceanogr. mar. Biol. 19, 141-234.

Vuorisalo, T. \& Tuomi, J., 1986. Unitary and modular organisms: criteria for ecological division. Oikos $47,382-384$. 